\title{
Immune-Specific Gamma Interferon Production Correlates with Lymphocyte Blastogenesis
}

\author{
ALAN D. D’ANDREA, 1.2 STANLEY A. PLOTKIN, 2.3 STEVEN D. DOUGLAS, 1.2 AND RICHARD A. POLIN $2.4 *$ \\ Divisions of Allergy-Immunology, ${ }^{1}$ Infectious Diseases, ${ }^{3}$ and Neonatology, ${ }^{4}$ Department of Pediatrics. The Children's \\ Hospital of Philadelphia and School of Medicine. University of Pennsylicania, Joseph Stokes Jr. Research Institute.2 \\ Philadelphia, Pennsylvania 19104
}

Received 15 October 1985/Accepted 3 February 1986

\begin{abstract}
Gamma interferon (IFN- $\gamma$ ) production, measured by a new commercially available radioimmunoassay, and lymphocyte blastogenesis were investigated in human peripheral lymphocyte cultures from healthy adults stimulated by crude cytomegalovirus (CMV) antigen. Mononuclear cells were obtained from 32 healthy adults (18 CMV seropositive $\left[S^{+}\right]$and $14 \mathrm{CMV}$ seronegative $\left[S^{-}\right]$) by Ficoll-Hypaque gradients and cultured in microtiter plates containing $\mathrm{CMV}$ antigen. Lymphocyte blastogenesis $\left(\left[{ }^{3} \mathrm{H}\right]\right.$ thymidine uptake) and IFN- $\gamma$ were determined on day 6 . The mean stimulation index for $S^{+}$individuals was significantly greater than that for $S^{-}$ individuals $(P<0.001)$. Similarly, the IFN- $\gamma$ stimulation index was greater for $S^{+}$individuals than for $S^{-}$ individuals $(P<0.005)$. A significant increase in the concentration of IFN- $\gamma(10 \mathrm{NIH}$ units/ml $)$ was observed for $\mathrm{S}^{+}$individuals at $24 \mathrm{~h}$ of antigen stimulation, with peak levels at 4 days. The radioimmunoassay for IFN- $\gamma$ production by antigen-stimulated lymphocytes in vitro (IMRX; Centocor Inc., Malvern, Pa.) is a rapid and sensitive measure of cell-mediated immunity.
\end{abstract}

Lymphocyte blastogenesis is usually employed as an in vitro system to assess cell-mediated immunity (14). There is an immune-specific production of the lymphokine gamma interferon (IFN- $\gamma$ ) when mononuclear cells are stimulated by a specific antigen. For example, mononuclear cells from seropositive donors produce IFN- $\gamma$ in response to viral antigens of herpes simplex virus $(8,9,13,15)$, Epstein-Barr virus (1), cytomegalovirus (CMV) (14), vaccinia virus (6), mumps virus (11), and influenza virus (5).

Previous studies have used a bioassay for IFN- $\gamma$; however, there is marked variability both in the time of earliest detection of IFN- $\gamma$ and in the day of maximum production $(1,8,11)$. Bioassays quantitate IFN- $\gamma$ on the basis of inhibition of viral growth in cultured cells. With the exception of a recently described spectrophotometric assay (7), they are limited by their dependence on subjective evaluation of tissue culture cell cytopathic changes and also by their failure to distinguish among the various subclasses of interferons (IFN- $\alpha$, IFN- $\beta$, and IFN- $\gamma$ ). The purpose of the current work was to quantitate IFN- $\gamma$ production by mononuclear cells from normal adults in response to a particular antigen (CMV antigen) by a radioimmunoassay (RIA) described by Chang et al. (4).

\section{MATERIALS AND METHODS}

Study population. Donors consisted of 32 healthy adult laboratory or hospital personnel ranging from 20 to 40 years of age. Plasma was assayed for CMV antibody by a commercially available CMV indirect hemagglutination assay, (Cetus CMV IHA). Of the donors, 18 seropositive and 14 seronegative individuals were identified in the study population. Of the seropositive donors, eight had received Towne strain CMV vaccine (12) within 1 year of blood drawing.

Preparation of mononuclear cells. Heparinized blood ( 10 $\mathrm{ml}$ ) was drawn from each volunteer. Mononuclear cells obtained by Ficoll-Hypaque centrifugặtion were suspended

\footnotetext{
* Corresponding author
}

at a concentration of $10^{6}$ cells per $\mathrm{ml}$ in RPMI 1640 (GIBCO Laboratories, Grand Island, N.Y.) with $15 \%$ autologous plasma.

Preparation of CMV antigen. CMV and control antigens were a generous gift from Stuart Starr. CMV antigen was prepared by infecting monolayers of WI-38 cells with the Towne strain of CMV at a multiplicity of infection of 0.1 (14). Infected cells were suspended in Eagle minimal essential medium containing $10 \%$ fetal calf serum and sonicated for $5 \mathrm{~s}$. Sonically treated materials were pooled and clarified by low-speed $(1,400 \times g)$ centrifugation. The resultant pool was assayed for CMV virions by plaque formation, diluted to $10^{5} \mathrm{PFU} / \mathrm{ml}$, heat inactivated $\left(56^{\circ} \mathrm{C}\right.$ for $\left.1 \mathrm{~h}\right)$, and stored at $-70^{\circ} \mathrm{C}$ until use. Control antigen was prepared analogously from uninfected WI-38 cells.

Lymphocyte blastogenesis assay. Mononuclear cells $(2 \times$ $10^{5}$ ) were added to round-bottomed microtiter plates (Linbro Scientific Co., Hamden. Conn.) at $0.2 \mathrm{ml}$ per well. CMV (final concentration of $10^{3}$ irradiated $\mathrm{PFU} / \mathrm{ml}$ ) or control antigen was added to triplicate cultures in a $0.01-\mathrm{ml}$ volume. As a positive control, phytohemagglutinin $(0.005 \mathrm{mg} / \mathrm{ml})$ or antigen prepared from tetanus toxoid $(0.025 \mathrm{mg} / \mathrm{ml})$ or varicella-zoster virus $\left(10^{3}\right.$ irradiated $\left.\mathrm{PFU} / \mathrm{ml}\right)$ was added to additional wells from each donor. Antigen-stimulated cul tures were incubated for 6 days in a $5 \% \mathrm{CO}_{2}$ atmosphere at $37^{\circ} \mathrm{C}$. Mitogen-stimulated cultures were incubated for 3 days. Tritiated thymidine $(6.7 \mathrm{Ci} / \mathrm{mmol}$ : New England Nuclear Corp., Boston. Mass.) was added for a final 4-h incubation. Supernatants of individual microtiter wells were removed with a Pasteur pipette and stored in $1.5-\mathrm{ml}$ conical tubes at $-70^{\circ} \mathrm{C}$. Cells were harvested and lymphocyte blastogenesis was calculated as described by Starr et al. (14).

IFN- $\gamma$ assay. IFN- $\gamma$ was assayed by an RIA supplied by Centocor, Inc., Malvern, Penn. (IMRX). IMRX is a solidphase RIA based on the "forward sandwich" principle. A polystyrene bead, coated with one mouse monoclonal antibody specific for human IFN- $\gamma$ was incubated for $2 \mathrm{~h}$ in a $200-\mu l$ volume of either the test culture supernatant (diluted $1: 2$ and $1: 10$ ), pooled, human serum or the vendor-supplied 



FIG. 1. Proliferative response and IFN- $\gamma$ response to antigen expressed as blastogenesis SI and IFN- $\gamma$ SI of mononuclear cell cultures from seropositive and seronegative individuals. Individual values are presented. For each group, the arithmetic mean \pm SD is shown by a bar. Symbols: ${ }^{*}, P<0.001 ; * *, P<0.005$.

standard or control supernatant. During this incubation, IFN- $\gamma$ in the specimen was bound to the solid phase. Unbound material was washed from the bead. Next, a second mouse antibody to human IFN- $\gamma$ labeled with ${ }^{125} \mathrm{I}$ was incubated with the bead. Unbound labeled antibody was washed away after a second $2-\mathrm{h}$ incubation, and radioactivity was determined by counting the bead in a gamma scintillation counter. Bound radioactivity was directly proportional to the concentration of the IFN- $\gamma$ present in the original specimen (measured in NIH units per milliliter). The IMRX assay has a sensitivity of $0.1 \mathrm{NIH}$ units/ml of IFN- $\gamma$ and a specificity for biologically active IFN- $\gamma$.

Calculation of SI. The stimulation index (SI) for blastogenesis was defined as the ratio of tritiated thymidine (in cpm) stimulated by CMV antigen divided by the tritiated thymidine (in cpm) stimulated by control antigen. Based upon previous investigations comparing large populations of seronegative and seropositive individuals, a ratio of greater than 2.0 was considered a positive assay (14), signifying cell-mediated immunity in vitro. The IFN- $\gamma$ SI was defined as the ratio of units of IFN- $\gamma$ stimulated by CMV antigen to the units of IFN- $\gamma$ stimulated by control antigen. A ratio of greater than 6.5 was arbitrarily selected to define a positive assay.

Statistical analysis. SI values for blastogenesis and IFN- $\gamma$ for seropositive and seronegative individuals were compared by Student's $t$ test.

\section{RESULTS}

The blastogenesis SIs for the 14 seronegative individuals ranged from 0.3 to 2.5 with a mean of 1.0 , while values for the 18 seropositive individuals ranged from 0.9 to 38.7 with a mean of $10.1(P<0.001)$ (Fig. 1). IFN- $\gamma$ SIs for the 14 seronegative donors ranged from 0.8 to 6.5 with a mean of 2.6, while those for the 18 seropositive donors ranged from
8.9 to 368.0 with a mean of $93.5(P<0.005)$ (Fig. 1). Of the samples showing a positive assay by blastogenesis SI $94 \%$ also had a positive assay by IFN- $\gamma$ SI, and of those samples showing a negative assay by blastogenesis SI $93 \%$ had a negative assay by IFN- $\gamma$ SI. Every donor demonstrated a significant increase in the number of $\mathrm{cpm}$ (ranging from 10,000 to 30,000 ) and increase in IFN- $\gamma$ production (ranging from 50 to $400 \mathrm{NIH}$ units $/ \mathrm{ml}$ ) with stimulation by phytohemagglutinin, tetanus toxoid, or varicella-zoster virus antigen.

Among the 18 seropositive individuals tests, 8 had seroconverted after receiving Towne strain CMV vaccine within the previous year, while 10 had achieved natural immunity from former undocumented wild-type infections. The mean blastogenesis SI for the Towne vaccinees was 14.5 , compared with a mean blastogenesis SI for the natural seroconverters of 6.5 (difference not statistically significant) (Fig. 2). The mean IFN- $\gamma$ SI for the Towne vaccinees was 163.9 , compared with a mean IFN- $\gamma$ SI for the natural seroconverters of $37.1(P<0.02)$.

Figure 3 demonstrates the net increase in cpm for the individual donors expressed as net $\mathrm{cpm}$ and net units of IFN- $\gamma$ per milliliter. The mean background $\mathrm{cpm}$ for the seronegative donors was 3,069 , and the mean background $\mathrm{cpm}$ for the seropositive donors was 2,259 . The mean net $\mathrm{cpm}$ for the seronegative donors was 995 , and the mean net cpm for the seropositive donors was $16,985(P<0.01)$. The mean net IFN- $\gamma$ production for seronegative donors was 5.8 $\mathrm{NIH}$ units $/ \mathrm{ml}$, and the mean net IFN- $\gamma$ production for seropositive donors was $73.5 \mathrm{NIH}$ units $/ \mathrm{ml}(P<0.01)$. Similar to the considerable variability of cell proliferation (measured as net cpm) among CMV-seropositive donors, there was a great deal of variability in IFN- $\gamma$ production. However, for any given individual, the magnitude of the antigen-stimulated proliferation (in net $\mathrm{cpm}$ ) did not correlate with the net increase in IFN- $\gamma$ by regression analysis. 

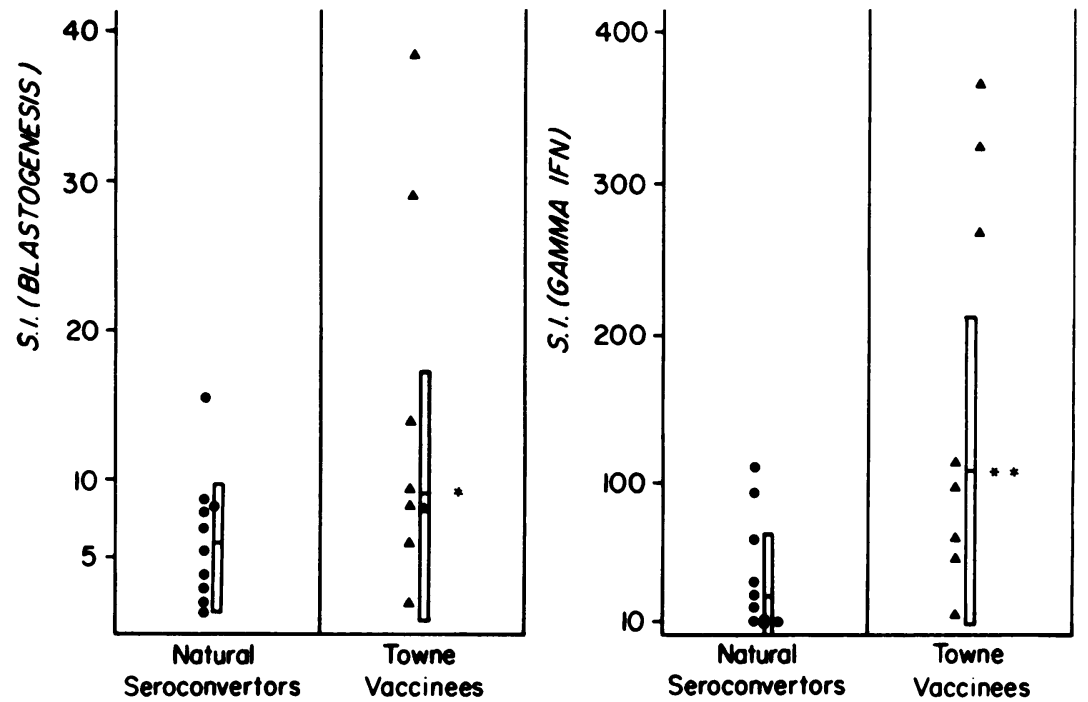

FIG. 2. Proliferative response and IFN- $\gamma$ response to CMV antigen expressed as blastogenesis SI and IFN- $\gamma$ SI of mononuclear cell cultures from natural seroconvertors and from recent Towne vaccinees. Individual values are presented. For each group, the arithmetic mean $\pm \mathrm{SD}$ is shown by a bar. Symbols: ${ }^{*}$, difference not statistically significant; ${ }^{* *}, P<0.02$.

The kinetics of IFN- $\gamma$ production after 8 days of CMV antigen stimulation is shown in Fig. 4. For the three seropositive individuals, readily detectable IFN- $\gamma$ concentrations were observed (greater than $10 \mathrm{NIH}$ units/ml) after only $24 \mathrm{~h}$ of stimulation. The maximum response occurred on day 4 to 6 and varied considerably in magnitude from 40 to over $200 \mathrm{NIH}$ units $/ \mathrm{ml}$. For the seronegative individuals, peak detectable IFN- $\gamma$ levels never exceeded $3.5 \mathrm{NIH}$ units/ml during the 8-day incubation. Differences in absolute IFN- $\gamma$ production between seronegative and seropositive individuals were observed as early as day 1 .

\section{DISCUSSION}

Our results indicate that mononuclear cells from CMVseropositive individuals produce IFN- $\gamma$ as an immunespecific response to crude CMV antigen, and these findings are consistent with published studies (14). Among the normal adults in the study group, there was a $94 \%$ concordance between blastogenesis SI, a commonly used laboratory tool to denote cell-mediated immunity in vitro, and IFN- $\gamma$ SI. Therefore, the blastogenesis SI and the IFN- $\gamma$ SI calculated after 6 days of antigen stimulation were comparable measures of cell-mediated immunity in vitro.
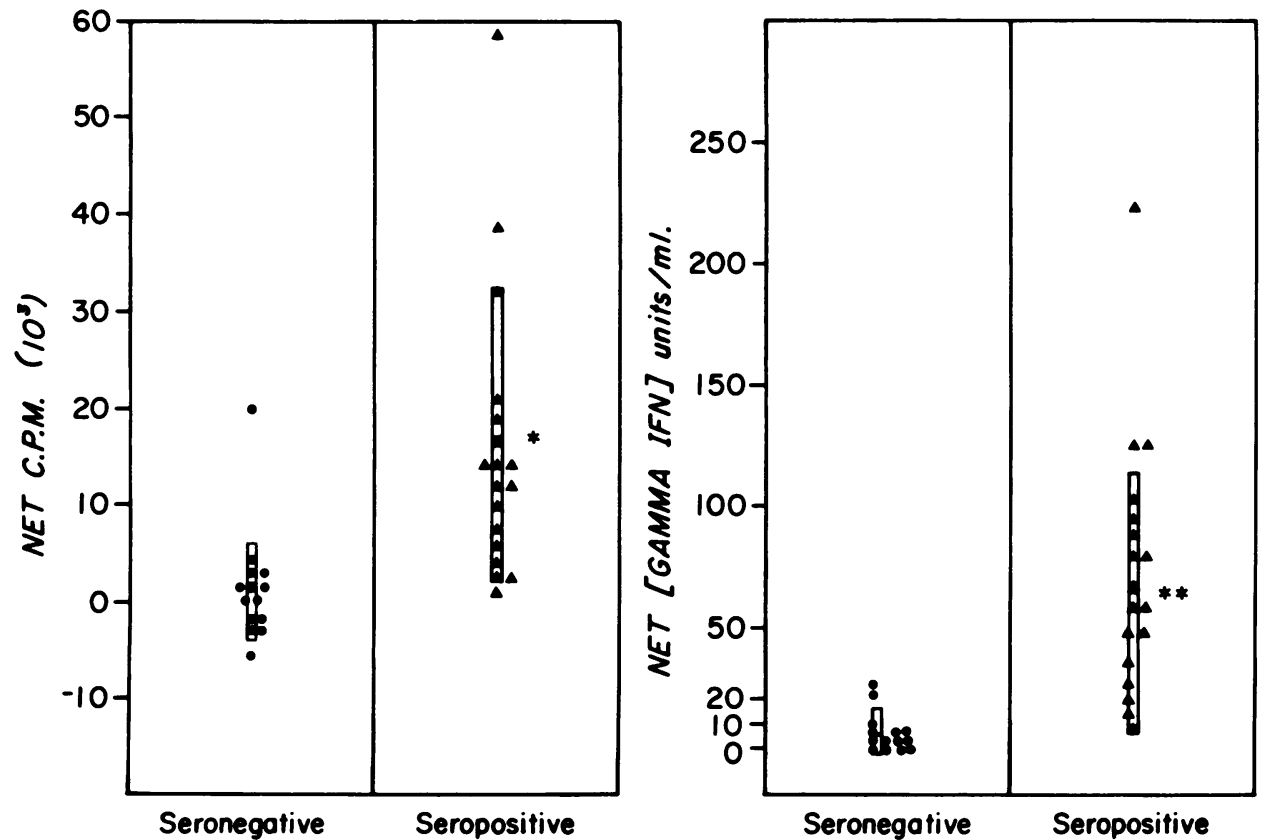

FIG. 3. Proliferative response and IFN- $\gamma$ response to $\mathrm{CMV}$ antigen expressed as net $\mathrm{cpm}$ for blastogenesis and net increase in IFN- $\gamma$ concentration for mononuclear cell cultures from seropositive and seronegative individuals. For each group, the arithmetic mean \pm SD is shown by a bar. Symbols: ${ }^{*}, P<0.01{ }^{* *}, P<0.01$. 


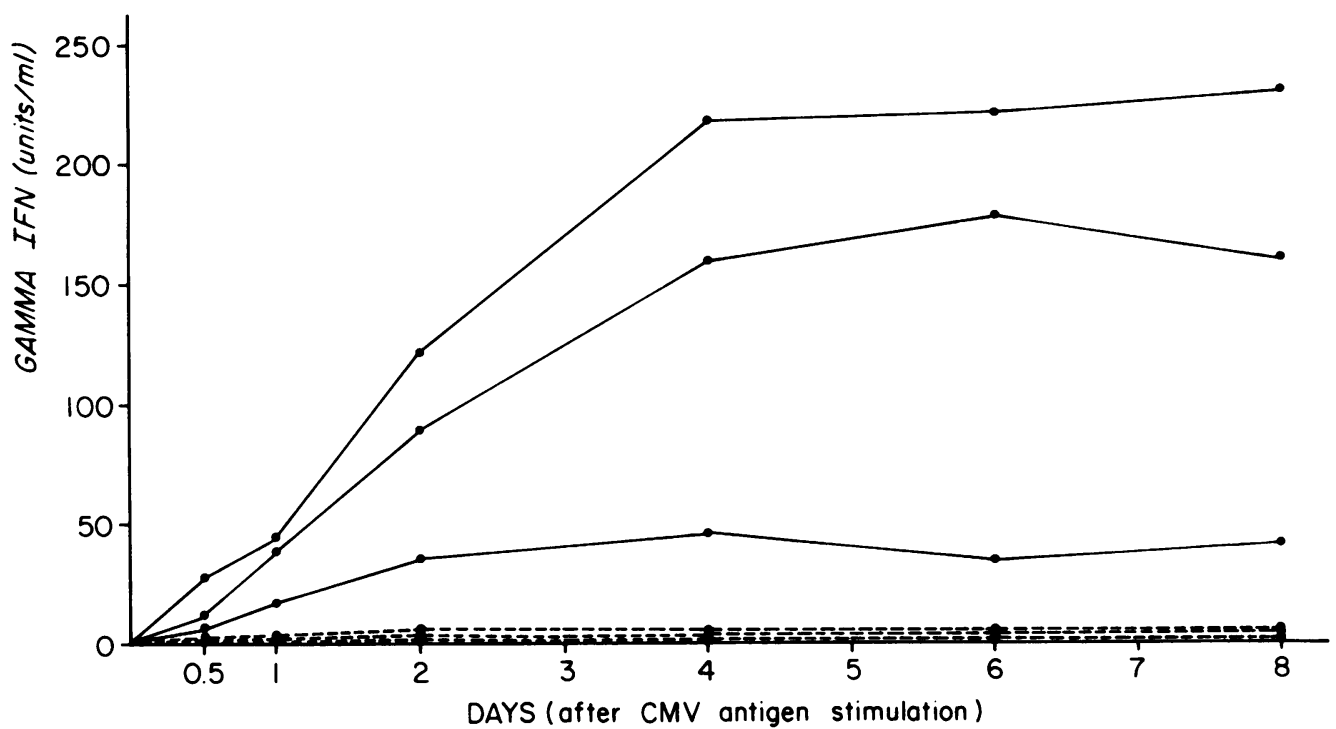

FIG. 4. Kinetics of IFN- $\gamma$ production in seropositive versus seronegative human blood mononuclear cultures. Mononuclear cell cultures were prepared by Ficoll-Hypaque gradient centrifugation from three seropositive $(-)$ and three seronegative (-----) individuals. Mononuclear cells $\left(2 \times 10^{5}, 200 \mu \mathrm{l}\right)$ from each donor were added to each of seven wells of a round-bottomed microtiter plate containing CMV antigen. At the indicated times, supernatant was removed from a well and frozen at $-70^{\circ} \mathrm{C}$ for determination of IFN- $\gamma$ concentration at a later date.

The RIA for IFN- $\gamma$ has several advantages over the conventional bioassay for this lymphokine. (i) The RIA offers a sensitivity of $0.1 \mathrm{NIH}$ units/ml and a specificity for biologically active IFN- $\gamma(4)$. In contrast, the bioassay had a sensitivity of 1 to $10 \mathrm{NIH}$ units/ml and fails to distinguish among IFN- $\alpha$, IFN- $\beta$, and IFN- $\gamma$. (ii) The RIA shows reproducibility with intra-assay coefficients of variation of less than $10 \%$ and provides standards of IFN $-\gamma$ which will not vary. (iii) The RIA is rapid, taking approximately 4 laboratory hours compared with 2 to 3 days for the standard bioassay. (iv) The large range of values generated for the IFN- $\gamma$ SI and for the net increase in IFN- $\gamma$ concentration may provide a means to distinguish recent and old seroconvertors and successful and abortive vaccinationinduced cell-mediated immunity.

Our study demonstrates that IFN- $\gamma$ is readily detectable by RIA as early as $24 \mathrm{~h}$ of antigen stimulation, and peak production occurs by day 4 to 6 of antigen stimulation. However, time of initial detection and maximum response may be highly dependent on specific viral antigen and potency, and extrapolation to other systems may not be possible. Although readily detectable differences in IFN- $\gamma$ production occurred between three seropositive individuals and three seronegative individuals as early as $24 \mathrm{~h}$ after in vitro stimulation with CMV antigen, a larger study group is required to determine whether this brief incubation time can consistently distinguish between individuals with and without cell-mediated immunity.

Despite the concordance between blastogenesis and IFN$\gamma$ production, there is no evidence that net proliferation of cells (as net $\mathrm{cpm}$ ) correlates with the net production of IFN- $\gamma$ for a particular individual. These two biological processes may both denote cell-mediated immunity in vitro but may also be independent processes by different subpopulations of cells. It may be useful for a clinical laboratory to measure both blastogenesis and IFN- $\gamma$ production to evaluate clinical states in which these functions may be dissociated, such as in normal neonates (3) and patients after bone marrow transplantation $(2,10)$.

\section{ACKNOWLEDGMENTS}

We gratefully acknowledge the laboratory assistance of $M$. Parente and L. Tyler. We thank S. Starr for helpful discussions and for supply of crude CMV antigen. We also thank S. Mosiniak for her technical assistance.

This work was supported in part by Public Health Service grants NS 17752, HL 27068, and HD 18957 from the National Institutes of Health and by a grant from the Hassel Foundation.

\section{LITERATURE CITED}

1. Andersson, U., O. Martinez-Maza, J. Andersson, S. Britton, $\mathbf{H}$. Gadler, M. De Ley, and S. Modrow. 1984. Secretion of $\gamma$ interferon at the cellular level: induction by Epstein-Barr virus. Scand. J. Immunol. 20:425-432.

2. Bryson, Y., S. Gard, B. Ank, and E. R. Stiehm. 1983. Studies of cellular immunity to cytomegalovirus and lymphokine production by lymphocytes of bone marrow transplant recipients, $p$. 321-327. In R. P. Gale (ed.), Proceedings of the ICN-UCLA Symposium on Biology of Bone Marrow Transplantation. Academic Press, Inc., New York.

3. Bryson, Y. J., H. S. Winter, S. E. Gard, T. J. Fischer, and E. R. Stiehm. 1980. Deficiency of immune interferon production by leukocytes of normal newborns. Cell. Immunol. 55:191-200.

4. Chang, T. W., S. McKinney, V. Liu, P. C. Kung, J. Vilcek, and J. Le. 1984. Use of monoclonal antibodies as sensitive and specific probes for biologically active human $\gamma$-interferon. Proc. Natl. Acad. Sci. USA 81:5219-5222.

5. Ennis, F. A., and A. Reager. 1981. Immune interferon produced to high levels by antigenic stimulation of human lymphocytes with influenza virus. J. Exp. Med. 154:1279-1284.

6. Epstein, L. B., D. A. Stevens, and T. C. Merigan. 1972. Selective increase in lymphocyte interferon response to vaccinia antigen after revaccination. Proc. Natl. Acad. Sci. USA 69:2632-2636.

7. Forti, R. L., R. A. Moldovan, W. M. Mitchell, P. Callicoat, S. S. Schuffman, H. A. Davies, and D. M. Smith, Jr. 1985. Application of an objective biological assay of human interferons to clinical specimens and a survey of a normal population. J. Clin. Microbiol. 21:689-693.

8. Green, J. A., T. Yeh, and J. C. Overall, Jr. 1981. Sequential production of IFN- $\gamma$ and immune-specific IFN- $\gamma$ by humanmononuclear leukocytes exposed to herpes simplex virus. J. Immunol. 127:1192-1196. 
9. Haahr, S., L. Rasmussen, and T. C. Merigan. 1976. Lymphocyte transformation and interferon production in human mononuclear cell microcultures for assay of cellular immunity to herpes simplex virus. Infect. Immun. 14:47-54.

10. Levin, M. J., R. Parkman, M. N. Oxman, J. M. Rappeport, M. Simpson, and P. L. Leary. 1978. Proliferative and interferon responses by peripheral blood mononuclear cells after bone marrow transplantation in humans. Infect. Immun. 20:678-684.

11. Nakayama, T. 1983. Immune-specific production of gamma interferon in human lymphocyte cultures in response to mumps virus. Infect. Immun. 40:486-492.

12. Plotkin, S. A., T. Furukawa, N. Zygraich, and C. Huygelen. 1975. Candidate cytomegalovirus strain for human vaccination.
J. Infect. Dis. 12:521-527.

13. Rasmussen, L. E., G. W. Jordan, D. A. Stevens, and T. C. Merigan. 1974. Lymphocyte interferon production and transformation after herpes simplex infections in humans. J. Immunol. 112:728-736.

14. Starr, S. E., B. Dalton, T. Garrabrant, K. Paucker, and S. A. Plotkin. 1980. Lymphocyte blastogenesis and interferon production in adult human leukocyte cultures stimulated with cytomegalovirus antigens. Infect. Immun. 30:17-22.

15. Valle, M. J., A. M. Bobiove, S. Strober, and T. C. Merigan. 1975. Immune specific production of interferon by human $T$ cells in combined macrophage-lymphocyte cultures in response to herpes simplex antigen. J. Immunol. 114:435-441. 